\title{
Ground-Based Infrared Measurements of Carbonyl Sulfide Total Column Abundances: Long-Term Trends and Variability
}

\author{
C. P. Rinsland, ${ }^{1}$ R. Zander, ${ }^{2}$ E. Mahieu, ${ }^{2}$ P. Demoulin, ${ }^{2}$ \\ A. Goldman, ${ }^{3}$ D. H. EhHalt,${ }^{4}$ AND J. RudolPh ${ }^{4}$
}

\begin{abstract}
Total vertical column abundances of carbonyl sulfide (OCS) have been derived from time series of high-resolution infrared solar absorption spectra recorded at the National Solar Observatory McMath solar telescope facility on Kitt Peak (altitude $2.09 \mathrm{~km}$, latitude $31.9^{\circ} \mathrm{N}$, longitude $111.6^{\circ} \mathrm{W}$ ), southwest of Tucson, Arizona, and at the International Scientific Station of the Jungfraujoch (altitude $3.58 \mathrm{~km}$, latitude $46.5^{\circ} \mathrm{N}$, longitude $8.0^{\circ} \mathrm{E}$ ), in the Swiss Alps. The analysis of both data sets is based on nonlinear least squares spectral fittings of narrow intervals centered on lines of the intense $\nu_{3}$ band of OCS, the $P(37)$ transition at $2045.5788 \mathrm{~cm}^{-1}$ and the $P(15)$ transition at $2055.8609 \mathrm{~cm}^{-1}$, with a consistent set of spectroscopic line parameters. The Kitt Peak measurements, recorded on 30 different days between May 1977 and March 1991, show a 10\% peak-to-peak seasonal cycle with a summer maximum and a winter minimum and a trend in the total column abundance equal to $(0.1 \pm 0.2) \% \mathrm{yr}^{-1}$, 2r. Jungfraujoch solar spectra recorded on 67 different days between October 1984 and April 1991 have been analyzed. The fitted trend in the Jungfraujoch total columns, $(-0.1 \pm 0.5) \% \mathrm{yr}^{-1}, 2 \sigma$, is consistent with the Kitt Peak trend results within the errors. The Jungfraujoch total columns show a more complex seasonal variation than noted in the Kitt Peak data. The mean of the daily averaged total columns, $8.44 \times 10^{15}$ molecules $\mathrm{cm}^{-2}$ above Kitt Peak and $6.41 \times 10^{15}$ molecules $\mathrm{cm}^{-2}$ above the Jungfraujoch station, correspond respectively to mean tropospheric mixing ratios of $0.54 \pm 0.04$ and $0.52 \pm 0.04$ parts per billion by volume; these values are consistent with previously reported remote and in situ measurements. Taken together, the results from the two sites indicate that there has been no significant change in the OCS total column abundance at northern mid-latitudes over the last decade.
\end{abstract}

\section{INTRODUCTION}

Carbonyl sulfide (OCS) is the predominant sulfur-bearing gas in the remote troposphere with an average concentration of about 500 parts per trillion by volume (pptv or $10^{-12} \mathrm{ppv}$ ) [Sandalls and Penkett, 1977; Maroulis et al., 1977; Torres et al., 1980; Rasmussen et al., 1982a, b; Carroll, 1985; Johnson and Harrison, 1986; Bates and Johnson, 1990; Johnson et al., 1990]. The lifetime of OCS in the troposphere is sufficiently long, roughly 2 to 7 years [Johnson, 1981; Khalil and Rasmussen, 1984], that substantial quantities of the gas may be transported into the lower stratosphere where it is the principal source of sulfur, except for $\mathrm{SO}_{2}$ injected by violent volcanic eruptions [e.g., World Meteorological Organization (WMO), 1986]. In the lower stratosphere, OCS is dissociated by solar ultraviolet radiation, and its products provide a continuous source of sulfur to sustain the stratospheric sulfate aerosol layer (located between altitudes of about 18 and $22 \mathrm{~km}$ ) which is important in the radiation budget and climate of our planet [Crutzen, 1976].

Current evidence suggests that the main sources of OCS are natural, with oceans, microbial processes in soils, and the conversion of $\mathrm{CS}_{2}$ (also predominately natural) contributing about 30, 20, and 30\%, respectively [Khalil and Ras-

\footnotetext{
${ }^{1}$ Atmospheric Sciences Division, NASA Langley Research Center, Hampton, Virginia.

${ }^{2}$ Institute of Astrophysics, University of Liège, Liège-Cointe, Belgium.

${ }^{3}$ Department of Physics, University of Denver, Denver, Colorado.

${ }^{4}$ Institut für Atmosphärische Chemie, Forschungszentrum Jülich, Jülich, Germany.

Copyright 1992 by the American Geophysical Union.

Paper number 92JD00040.

0148-0227/92/92JD-00040\$05.00
}

mussen, 1984]. Khalil and Rasmussen [1984] inferred a northern-to-southern interhemispheric ratio (IHR) of 1.05 from published OCS measurements [Torres et al., 1980], and used this result to deduce that only about $25 \%$ of the OCS in the atmosphere results from direct and indirect $\left(\mathrm{CS}_{2}\right.$ to OCS conversion) anthropogenic activities. The largest anthropogenic source is emissions from biomass burning, about $10 \%$ [Khalil and Rasmussen, 1984; Crutzen and Andreae, 1990], followed by releases from coal-fired power plants (about $4 \%$ ), and automobiles, chemical industry, and sulfur recovery processes (about 3\%) [Khalil and Rasmussen, 1984].

Khalil and Rasmussen [1984] noted that the magnitude of the OCS IHR is uncertain, and pointed to the possibility that anthropogenic emissions may be more important in the global OCS cycle than they estimated. Turco et al. [1980] concluded that as much as $50 \%$ of OCS emissions may be anthropogenic. Recently, Bingemer et al. [1990] measured a pronounced northward increase in OCS concentrations $21 \mathrm{~m}$ above the Atlantic Ocean between $37^{\circ} \mathrm{S}$ and $51^{\circ} \mathrm{N}$. On the basis of these results, Bingemer et al. [1990] derived a mean IHR of 1.25 . They speculated that their high IHR measurement and a strong correlation observed between the concentrations of $\mathrm{OCS}$ and both $\mathrm{CO}$ and $\mathrm{CH}_{4}$ could be explained by continental OCS sources larger than previously estimated [Khalil and Rasmussen, 1984] and that these sources would be mostly anthropogenic. It should be noted, however, that the IHR measured by Bingemer et al. [1990] is significantly higher than indicated by three recent tropospheric data sets [Carroll, 1985; Johnson and Harrison, 1986; Johnson et al., 1990], as well as the earlier data set of Torres et al. [1980], and that the high measured latitudinal variation could be part of a seasonal signal caused by uptake of OCS by vegetation [Bingemer et al., 1990].

The possibility that anthropogenic sources may be important in the OCS budget has led to speculation that the 
atmospheric concentrations of OCS are increasing with time. Khalil and Rasmussen [1984] concluded that if the anthropogenic component of the global emissions is growing by $(2.5-3.5) \% \mathrm{yr}^{-1}$, the global OCS concentration may rise by $(0.6-0.8) \% \mathrm{yr}^{-1}$. Turco et al. [1980] pointed out that increasing OCS concentrations could increase the mass of the stratospheric aerosol layer, resulting in radiative effects which could produce measurable changes in the Earth's climate within the next century. Hofmann [1990] noted that in addition to important climate implications, an increase in the stratospheric sulfate aerosol mass could produce heterogeneous chemical reactions which might alter the concentration of stratospheric ozone. These effects could also lead to changes in the concentrations of other key stratospheric species, such as $\mathrm{NO}_{2}$ and $\mathrm{HNO}_{3}$ (see the results of Hofmann and Solomon [1989]). Although an increase in the background stratospheric sulfuric acid aerosol mass at northern mid-latitudes has been reported [Hofmann and Rosen, 1980; Hofmann, 1990], the observed increase rate is too rapid to be due to OCS alone [Hofmann, 1991]. It has been hypothesized that additional sources, particularly sulfur emitted by jet aircraft flying in the $11-12 \mathrm{~km}$ region, must be responsible for most of the increase [Hofmann, 1991].

In view of these studies it is clearly useful to have precise, long-term sets of atmospheric OCS measurements for trend evaluation. Such data might also reveal seasonal changes that could be related to interannual variations in the strengths of OCS sources and sinks. In the present investigation we report results based on the analysis of two OCS absorption lines in a time series of high-resolution infrared solar spectra recorded from the ground at two remote, high-altitude stations. The IR measurements from the one station, the National Solar Observatory facility on Kitt Peak (KP) in southern Arizona, cover the time period May 1977 to March 1991. The other measurements were recorded between October 1984 and April 1991 at the International Scientific Station of the Jungfraujoch (ISSJ), in the Swiss Alps. The spectral data from the two sites have been fitted with a nonlinear least squares procedure to retrieve OCS total column amounts which have been further analyzed to deduce information on long-term trends, seasonal changes, and variability.

\section{ObSERVATIONS AND ANALYSIS}

The present work is a continuation of a program undertaken to measure the long-term trends and seasonal cycles of key atmospheric constituents from high-resolution infrared solar spectra recorded with Fourier transform spectrometer (FTS) instruments at the KP and ISSJ stations. Details of the methods of analysis have been described previously [cf. Ehhalt et al., 1991; Rinsland et al., 1989, 1991a, b; Zander et al., 1989a, b, 1991], and therefore we report here only a brief overview and the essential information relevant to the present investigation.

Table 1 summarizes the measurement parameters for the solar spectra analyzed in the present study. Both FTS instruments are custom built. The ISSJ FTS was developed at the University of Liège in the mid-1970s [Malbromck, 1977]; since then, it has been significantly improved in terms of spectral resolution, spectral coverage, and scanning speed. All of the ISSJ spectra analyzed here were recorded and processed by $\mathrm{P}$. Demoulin. The design and performance
TABLE 1. Parameters for the Spectral Data Sets Analyzed in This Investigation

\begin{tabular}{lcc}
\hline & \multicolumn{2}{c}{ Value Corresponding to } \\
the Station
\end{tabular}

*The resolution is defined as $0.5 / L_{\max }$, where $L_{\max }$ is the maximum one-sided path difference.

of the KP instrument has been described by Brault [1978]. The Kitt Peak solar spectra were obtained by several investigators. The 1977 to 1979 observations were acquired by Delbouille et al. [1981]. Solar spectra recorded between 1980 to 1985 were obtained as a byproduct of the Battelle/Kitt Peak telluric spectrum program [Stokes et al., 1980] and were followed by observations by C. P. Rinsland from 1988 to 1991 .

For most of the Kitt Peak observations, pressuretemperature profiles calculated by the National Meteorological Center (NMC) for that location and the measurement dates (K. W. Johnson and M. Gelman, private communication, 1987-1991) were assumed. In a few cases we adopted pressure-temperature soundings acquired by radiosondes released from the Tucson airport, some $60 \mathrm{~km}$ northeast of Kitt Peak. A mid-latitude reference atmosphere selected from among several standard physical models (U.S. Standard Atmosphere, 1966, 1976) was assumed for the analysis of the remaining Kitt Peak and all of the Jungfraujoch observations.

The OCS total columns were retrieved with a nonlinear least squares spectral fitting algorithm that computed synthetic spectra by line-by-line techniques and a multilayer model atmosphere extending from the altitude of the observing site to $100 \mathrm{~km}$. For the present work we used a total of 29 layers with vertical thicknesses of $2 \mathrm{~km}$ or less below 32-km altitude. The total vertical column amount of each target molecule was retrieved from a spectrum by scaling an assumed relative volume mixing ratio (VMR) profile by a single multiplicative factor, which was iteratively adjusted along with the values of a number of instrumental parameters (e.g., a wave number shift between the measured and calculated spectra). The adjustments continued until the sum of the squares of the residuals (measured minus calculated signals) was minimized. The total column amount was obtained by summing the scaled vertical absorber column amount from all layers.

The assumed OCS relative VMR profile was based mostly on published measurements with some input from model calculations. An examination of the few reported strato- 
TABLE 2. OCS Profile Distributions Assumed in the Analysis

\begin{tabular}{ccc}
\hline \multirow{2}{*}{$\begin{array}{c}\text { Altitude, } \\
\text { km }\end{array}$} & \multicolumn{2}{c}{ OCS Volume Mixing Ratio, pptv } \\
\cline { 2 - 3 }$\leq 12.5$ & Profile I & Profile II \\
15.0 & 590 & 590 \\
17.5 & 550 & 510 \\
20.0 & 500 & 300 \\
22.5 & 380 & 250 \\
25.0 & 230 & 150 \\
\hline
\end{tabular}

spheric profile measurements suggests that the OCS volume mixing ratio above $20 \mathrm{~km}$ decreases more rapidly with altitude at high latitudes than at low latitudes (compare, for example, the measurements obtained by Inn et al. [1981] near $20 \mathrm{~km}$ in California and Alaska; also, contrast the $28^{\circ} \mathrm{N}$ and $48^{\circ} \mathrm{S}$ measurements derived from the ATMOS/Spacelab 3 spectra [Zander et al., 1988] and the $43^{\circ} \mathrm{N}$ IR balloon flight data of Louisnard et al. [1983]). However, more data are needed to verify this conjecture. To investigate the sensitivity of our retrievals to the assumed stratospheric OCS distribution, we performed retrievals with two profiles having different rates of VMR decrease above the tropopause. The two assumed vertical profiles are listed in Table 2. For profile I the ATMOS/Spacelab 3 measurements at $28^{\circ} \mathrm{N}$ [Zander et al., 1988, Table 3] were adopted and extended below $12.5 \mathrm{~km}$, the lowest measured altitude, by assuming a constant VMR equal to the retrieved value at $12.5 \mathrm{~km}$. Profile II assumes the $48^{\circ} \mathrm{S}$ ATMOS/Spacelab 3 measurements [Zander et al., 1988, Table 3]; it has been extrapolated below the lowest measured altitude of $17.5 \mathrm{~km}$ using the model profile of N. D. Sze reported by Zander et al. [1988, Figure 6] as a guide and assuming a constant mixing ratio of 590 pptv in the troposphere. The assumption of a constant tropospheric VMR is consistent with previous measurements [e.g., Rasmussen et al., 1982b. Figure 2] and the relatively long tropospheric lifetime of OCS. The vertical profiles of all other gases were taken from Smith [1982].

The total columns were derived by fitting two spectral regions, each one centered on a line in the OCS $\nu_{3}$ fundamental band, which is about 2 orders of magnitude stronger than any other OCS IR band [cf. Kagann, 1982]. Note that this band is sometimes labeled $\nu_{1}$ rather than $\nu_{3}$ [e.g., Wells et al., 1990]. The target transitions were selected by comparing the measured solar spectra with line-by-line simulations generated with the spectroscopic parameters discussed below. These calculations show that the lines of the OCS $\nu_{3}$ band are overlapped by absorption features due to several other telluric gases, mainly $\mathrm{H}_{2} \mathrm{O}, \mathrm{CO}_{2}, \mathrm{O}_{3}$, and $\mathrm{CO}$, and by lines of the $\Delta v=1$ vibration-rotation sequence of solar $\mathrm{CO}$. No OCS lines are completely free of interferences. The two

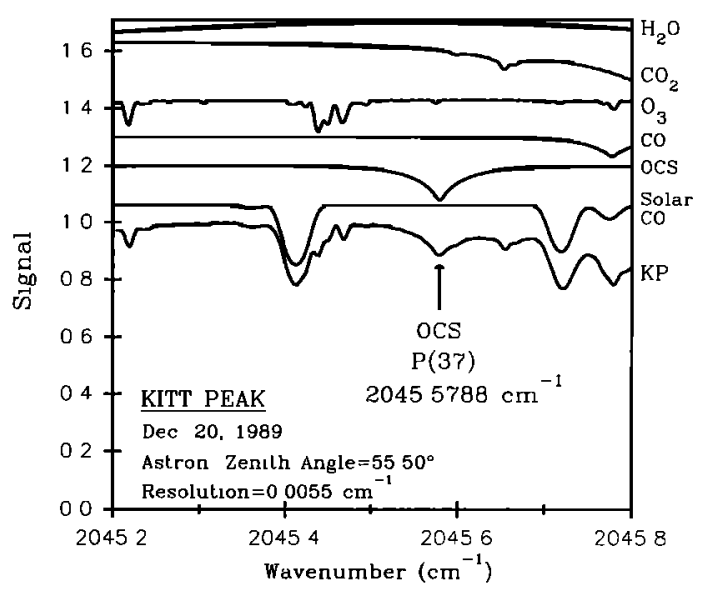

Fig. 1. Simulations of the atmospheric absorption by the gases $\mathrm{H}_{2} \mathrm{O}, \mathrm{CO}_{2}, \mathrm{O}_{3}, \mathrm{CO}$, and $\mathrm{OCS}$ using realistuc VMR profiles (upper five spectra), a simulation of the absorption by solar $\mathrm{CO}$ (second spectrum from the bottom), and a Kitt Peak solar spectrum (bottom spectrum) in the region of the OCS $\nu_{3}$ band $P(37)$ line at 2045.5788 $\mathrm{cm}^{-1}$. The simulated and measured spectra are offset vertically for clarity. An arrow beneath the bottom spectrum marks the location of the OCS line.

selected microwindows (2045.20-2045.80 $\mathrm{cm}^{-1}$ and 2055.64 $2055.97 \mathrm{~cm}^{-1}$ ) contain the $P(37)$ OCS transition at 2045.5788 $\mathrm{cm}^{-1}$ and the $P(15)$ OCS transition at $2055.8609 \mathrm{~cm}^{-1}$, respectively. These lines were judged as the best ones for ground-based retrievals because they are least affected by the interferences. Also, calculations indicate that the variation of the line intensities with temperature, about $+\mathbf{0 . 3 \%}$ and $-0.3 \%$ per degree Kelvin at $250 \mathrm{~K}$ for $P(37)$ and $P(15)$, respectively, is minimized by averaging the results from the two microwindows.

Table 3 lists the OCS spectroscopic parameters assumed in the present work. The air-broadening coefficients at $296 \mathrm{~K}$ were obtained by fitting the values reported by Bouanich et al. [1987] to a polynomial in $|m|$, where $m$ is $J+1$ in the $R$ branch and $-J$ in the $P$ branch. The line parameters for ozone were taken from Rinsland et al. [1988] and CamyPeyret et al. [1990]. All other spectroscopic data for both OCS and the interfering species were taken from the 1986 HITRAN line parameters compilation [Rothman et al., 1987]. Recently, improved line positions have been derived for the OCS $\nu_{3}$ band by Wells et al. [1990]. These revised positions for $\boldsymbol{P}(37)$ and $\boldsymbol{P}(15)$ are, respectively, 0.00034 and $0.00040 \mathrm{~cm}^{-1}$ lower than the values listed in Table 3 . Sample fittings have shown that the revised positions change the retrieved OCS total columns by less than $1 \%$.

Figure 1 illustrates the complex atmospheric and solar absorptions in the microwindow containing the $P(37)$ OCS

TABLE 3. OCS Line Parameters Assumed in the Present Analysis

\begin{tabular}{ccccc}
\hline $\begin{array}{c}\text { Rotational } \\
\text { Assignment }\end{array}$ & $\begin{array}{c}\text { Position. } \\
\mathrm{cm}^{-1}\end{array}$ & $\begin{array}{c}\text { Intensity } \\
\text { at } 296 \mathrm{~K}\end{array}$ & $\begin{array}{c}\text { Lorentz } \\
\text { Coefficient } \\
\text { at 296 K }\end{array}$ & $\begin{array}{c}\text { Lower State } \\
\text { Energy, } \\
\mathrm{cm}^{-1}\end{array}$ \\
\hline$P(37)$ & 2045.5788 & $7.13 \times 10^{-19}$ & 0.0876 & 285.131 \\
$P(15)$ & 2055.8609 & $9.17 \times 10^{-19}$ & 0.0964 & 48.683 \\
\hline
\end{tabular}

Line intensities are in units of $\mathrm{cm}^{-1} /$ molecule $\mathrm{cm}^{-2}$. The broadening coefficients are in units of $\mathrm{cm}^{-1} \mathrm{~atm}^{-1}$ with an assumed $T^{-1}$ temperature dependence computed with $n=0.50$. 
line. The simulated transmission spectra for the four most important interfering telluric molecules, the target OCS gas, and solar CO lines, all offset vertically for clarity, are plotted from top to bottom. At the bottom a Kitt Peak spectrum recorded on December 20, 1989, at a mean astronomical zenith angle of $55.50^{\circ}$ is plotted; the simulations have been generated to correspond to these conditions. There is good correspondence between the positions and strengths of the features in the measured spectrum and those in the simulated spectra. Note that the solar CO lines are quite prominent. The procedure used to simulate and least squares fit the solar $\mathrm{CO}$ features has been described by Rinsland et al. [1982].

A sample fit of the $P(37)$ microwindow in an ISSJ spectrum recorded on October 24, 1987, is displayed in Figure 2. The amplitudes of the residuals of the fit are about a factor of 5 higher than the noise level of the data (the continuum signal-to-rms noise is $\sim 1400$ ). The fitting errors can be noted by comparing the measured and best fit synthetic spectra, for example near $2045.37 \mathrm{~cm}^{-1}$, which corresponds to the wing of a strong solar $\mathrm{CO}$ line. These discrepancies are probably the result of errors in the assumed line parameters, weak lines missing from the spectroscopic data base, and inadequacies in the modeling of the solar $\mathrm{CO}$ features. Residuals resulting from fittings in the $P(15)$ OCS microwindow are similar to those shown in Figure 2 for $P(37)$.

Table 4 lists the most important random and systematic sources of error and their magnitudes for a typical spectrum. The values have been estimated as described previously [e.g., Rinsland et al., 1984, 1985; Zander et al., 1989a, b; Ehhalt et al., 1991]. The uncertainties due to the random error sources can be reduced by averaging the various measurements on each day and assigning a corresponding uncertainty equal to the random error for a single observation divided by the square root of the number of measurements being averaged. As can be noted from Table 4 , the most important source of random error is the fitting of the interfering lines, both telluric and solar, in the two microwindows. Because the fittings show systematic errors in the
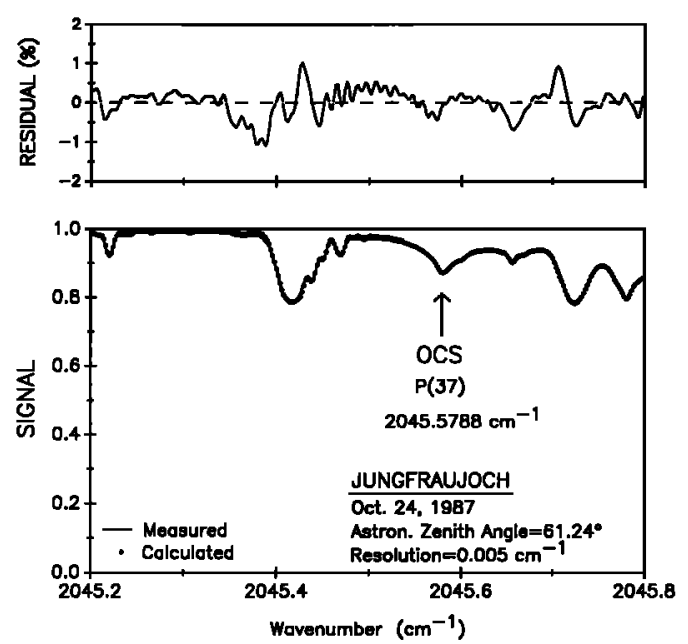

Fig. 2. Sample fitting results for the OCS $P(37)$ line at 2045.5788 $\mathrm{cm}^{-1}$. In the lower panel are presented a measured spectrum recorded from the Jungfraujoch station (solid line) and a least squares best fit to the data (open diamonds). An arrow beneath the spectra marks the location of the OCS line. The upper panel shows the residuals (measured minus simulated signals) on a expanded vertical scale.
TABLE 4. Error Sources and the Resulting Uncertainties in the Retrieved OCS Total Column Abundance for a Typical Spectrum

\begin{tabular}{|c|c|c|c|}
\hline \multirow[b]{2}{*}{ Error Source } & \multirow[b]{2}{*}{$\begin{array}{l}\text { Error } \\
\text { Type* }\end{array}$} & \multicolumn{2}{|c|}{$\begin{array}{c}\text { Percent Error in Total } \\
\text { Column }{ }^{\dagger}\end{array}$} \\
\hline & & $\begin{array}{l}\text { 1977-1991 } \\
\text { Kitt Peak }\end{array}$ & $\begin{array}{l}\text { 1984-1991 } \\
\text { ISSJ }\end{array}$ \\
\hline Finite signal-to-noise & $\mathbf{R}$ & 1.0 & 1.0 \\
\hline Error in $100 \%$ transmission level & $\mathbf{R}$ & 2.0 & 2.0 \\
\hline Zenith angle uncertainty & $\mathbf{R}$ & 2.0 & 1.5 \\
\hline Zero transmission offsets & $\mathbf{R}$ & 2.0 & 2.0 \\
\hline $\begin{array}{l}\text { Error in modeling instrument line } \\
\text { shape }\end{array}$ & S & 1.0 & 1.0 \\
\hline Pressure-temperature profile & $\mathbf{R}$ & 0.5 & 1.0 \\
\hline $\begin{array}{l}\text { Uncertainty in the assumed OCS } \\
\text { vertical profile distribution }\end{array}$ & $\mathbf{S}$ & 4.0 & 4.0 \\
\hline $\begin{array}{l}\text { Variability in the assumed OCS } \\
\text { vertical profile distribution }\end{array}$ & $\mathbf{R}$ & 2.0 & 2.0 \\
\hline $\begin{array}{l}\text { Spectroscopic parameters } \\
\text { uncertainties }\end{array}$ & $\mathbf{S}$ & 5.0 & 5.0 \\
\hline Fitting of interfering lines & $\mathbf{R}$ & 4.0 & 4.0 \\
\hline Modeling of interfering lines & $\mathbf{S}$ & 2.0 & 2.0 \\
\hline \multirow[t]{2}{*}{ Root-sum-square total } & $\mathbf{R}$ & 5.8 & 5.7 \\
\hline & $\mathbf{S}$ & 6.8 & 6.8 \\
\hline
\end{tabular}

${ }^{*} \mathrm{R}$ : random; $\mathrm{S}$ : systematic.

$\dagger$ Percent error with $1-\sigma$ uncertainty.

residuals (e.g., Figure 2), we also included a systematic error of $2 \%$ to account for the possibility that the results may be biased by errors in the modeling of the interfering lines. Systematic retrieval errors are dominated by the uncertainties in the assumed vertical profile distribution and the assumed spectroscopic parameters, particularly the intensities. The relative difference between the total columns retrieved with profiles I and II is taken as an estimate of the uncertainty due to errors in the vertical OCS distribution. In most cases the KP fitting residuals were slightly smaller with profile I, whereas the ISSJ fitting residuals were slightly reduced with profile II. These results support our conjecture of a more rapid vertical decline in the OCS stratospheric VMR at high latitudes than at low latitudes.

\section{Results and Discussion}

In Figure 3 the total column measurements from (upper panel) Kitt Peak and (lower panel) ISSJ are plotted versus time. The values are daily averages with the error bars representing the $1-\sigma$ precisions computed from the root-sumsquare of the random error sources (Table 4). The Kitt Peak data cover 30 days between May 1977 and March 1991, whereas the ISSJ data analyzed here comprise 67 measurement days from October 1984 to April 1991 out of a total of over 150 days covered during that period. The ISSJ data span a shorter time interval, but the measurements are more uniformly distributed in time.

Regarding both data sets, the retrieved total column amounts from a given day show no obvious dependence on the airmass of the observations or systematic differences in the results from the two microwindows. Consistent with the relatively long atmospheric lifetime of OCS, we found no evidence for diurnal changes in the total columns. Also, for a given day the differences among the retrieved total columns were less than the estimated precisions, indicating that short-term variability in the OCS total column did not exceed $\sim 5 \%$. 

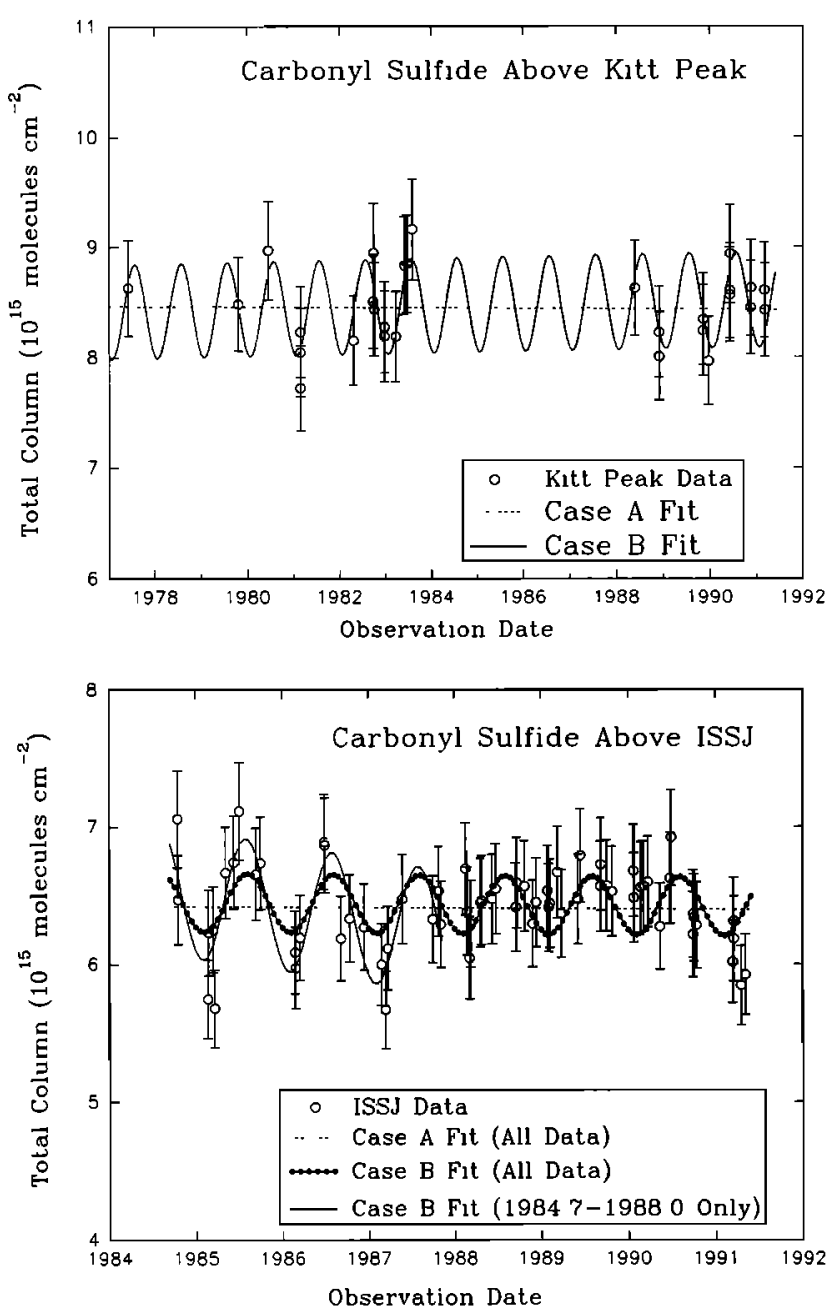

Fig. 3. Daily averaged measurements of the total vertical column of carbonyl sulfide above (upper panel) Kitt Peak and (lower panel) ISSJ plotted versus measurement date (e.g.. 1986.0 = January 1,1986$)$. Error bars indicate the estimated $1-\sigma$ precision. See text for a description of cases $\mathrm{A}$ and $\mathrm{B}$.

The investigation of the measured total columns to derive seasonal cycles and trends follows the procedure described in recent papers [Rinsland et al., 1991a,b]. In case A we assume that the OCS total column amount is changing at an exponential rate, that is,

$$
C_{A}=C_{0} \exp \left[\beta\left(t-t_{0}\right)\right]
$$

where $C_{A}$ is the total column at time $t, C_{0}$ is the total column at the reference time $t_{0}$, and $\beta$ is the rate of change, which is assumed not to vary with time. In case B the exponential total column change is assumed to be superimposed on a sinusoidal seasonal cycle

$$
C_{s}=a_{0} \cos \left\{2 \pi\left[\left(t-t_{0}\right)-t_{1}\right]\right\}
$$

where $C_{3}$ is the relative amplitude at time $t, a_{0}$ is the peak relative amplitude, and $t_{1}$ is the fraction of the calendar year corresponding to the time of the seasonal maximum. The case $\mathrm{B}$ total columns $C_{B}$ are then calculated by combining (1) and (2) assuming

$$
C_{B}=C_{A}\left(1+C_{\sqrt{ }}\right)
$$

The sum of the squares of the residuals (the measured minus calculated total columns) was minimized in the least squares fits to the measurements. The case $A$ and $B$ results are reported in Table 5 and displayed in Figure 3 with dashed and solid curves, respectively.

The upper panel of Figure 4 shows the residuals from the Kitt Peak case A fit plotted versus the time of the calendar year (e.g., $0.0=$ January 1). The plot shows a distinct seasonal variation with a summer maximum and a winter minimum. The sinusoidal (solid) curve in the upper panel illustrates the seasonal cycle computed with the coefficients derived from the case $B$ analysis; the curve reproduces the seasonal variation in the KP residuals very well. The standard deviation of the case $\mathrm{B}$ fit is almost a factor of 2 less than the standard deviation of the case A fit. The peak-topeak amplitude of the seasonal variation is about $10 \%$.

The lower panel of Figure 4 shows a sample of NMC tropopause heights for a latitude and longitude range centered on the geographical coordinates of Kitt Peak along with a sinusoidal function (solid curve) fitted to the data. A similarity in the seasonal variations of the quantities plotted in the two panels of Figure 4 is apparent. Zander et al. [1989a] proposed a connection between the total column seasonal variations of the long-lived gases and the seasonal changes in the altitude of the tropopause. The Kitt Peak OCS seasonal variations are consistent with this idea.

An estimate of the effects of the tropopause height variations on the Kitt Peak total column has been derived by raising and lowering the assumed OCS VMR profile in altitude by an amount equal to the changes given by the curve in the lower panel of Figure 4. The OCS VMR up to the altitude of the tropopause is assumed not to vary with time. The calculated amplitude of the seasonal variation in the total column is about $2 \%$ as compared to the observed amplitude of $(5.1 \pm 1.4) \%$. Hence the tropopause height changes may be responsible for about one-half of observed $\mathrm{KP}$ seasonal variation. The remaining ( $\sim 3 \%$ amplitude) $\mathrm{KP}$ seasonal variation is likely to be caused by changes in the average tropospheric OCS VMR.

The ISSJ residuals in Figure 3 show a more complex seasonal variation than the changes in the Kitt Peak data. A pronounced seasonal component can be noted during the

TABLE 5. Case A and Case B Coefficients Obtained From Fits

\begin{tabular}{|c|c|c|c|}
\hline \multirow[b]{2}{*}{ Coefficient } & \multirow{2}{*}{$\begin{array}{l}\text { Kitt Peak, } \\
\text { 1977-199I }\end{array}$} & \multicolumn{2}{|c|}{ ISSJ } \\
\hline & & $1984-1987$ & $1984-1991$ \\
\hline \multicolumn{4}{|c|}{ Case $A$} \\
\hline $\begin{array}{l}\beta \\
C_{0}\end{array}$ & $\begin{array}{c}0.0 \pm 0.4 \\
8.44 \pm 0.13\end{array}$ & $\begin{aligned}-1.0 & \pm 2.5 \\
6.39 & \pm 0.16\end{aligned}$ & $\begin{aligned}-0.1 & \pm 0.6 \\
6.42 & \pm 0.12\end{aligned}$ \\
\hline \multicolumn{4}{|c|}{ Case B } \\
\hline$\beta$ & $0.1 \pm 0.2$ & $-1.5 \pm 1.6$ & $-0.1 \pm 0.5$ \\
\hline$C_{0}$ & $8.48 \pm 0.08$ & $6.41 \pm 0.10$ & $6.45 \pm 0.10$ \\
\hline$a_{0}$ & $0.051 \pm 0.014$ & $0.072 \pm 0.024$ & $0.033 \pm 0.016$ \\
\hline$t_{1}$ & $0.557 \pm 0.038$ & $0.579 \pm 0.048$ & $0.592 \pm 0.074$ \\
\hline
\end{tabular}
to the Measured Kitt Peak and ISSJ Carbonyl Sulfide Total Vertical Column Amounts

Two-sigma error limits are listed. The standard deviations of the fits to the Kitt Peak measurements are 0.350 (case A) and 0.208 (case $B$ ) in units of $10^{15}$ molecules $\mathrm{cm}^{-2}$. Standard deviations of the fits to the ISSJ 1984-1991 measurements are 0.305 (case A) and 0.270 (case $B$ ) in units of $10^{15}$ molecules $\mathrm{cm}^{-2}$. Units are $\% \mathrm{yr}^{-1}$ for $\beta$ and $10^{15}$ molecules $\mathrm{cm}^{-2}$ for $C_{0}$. The reference date $t_{0}$ is 1986.0. 

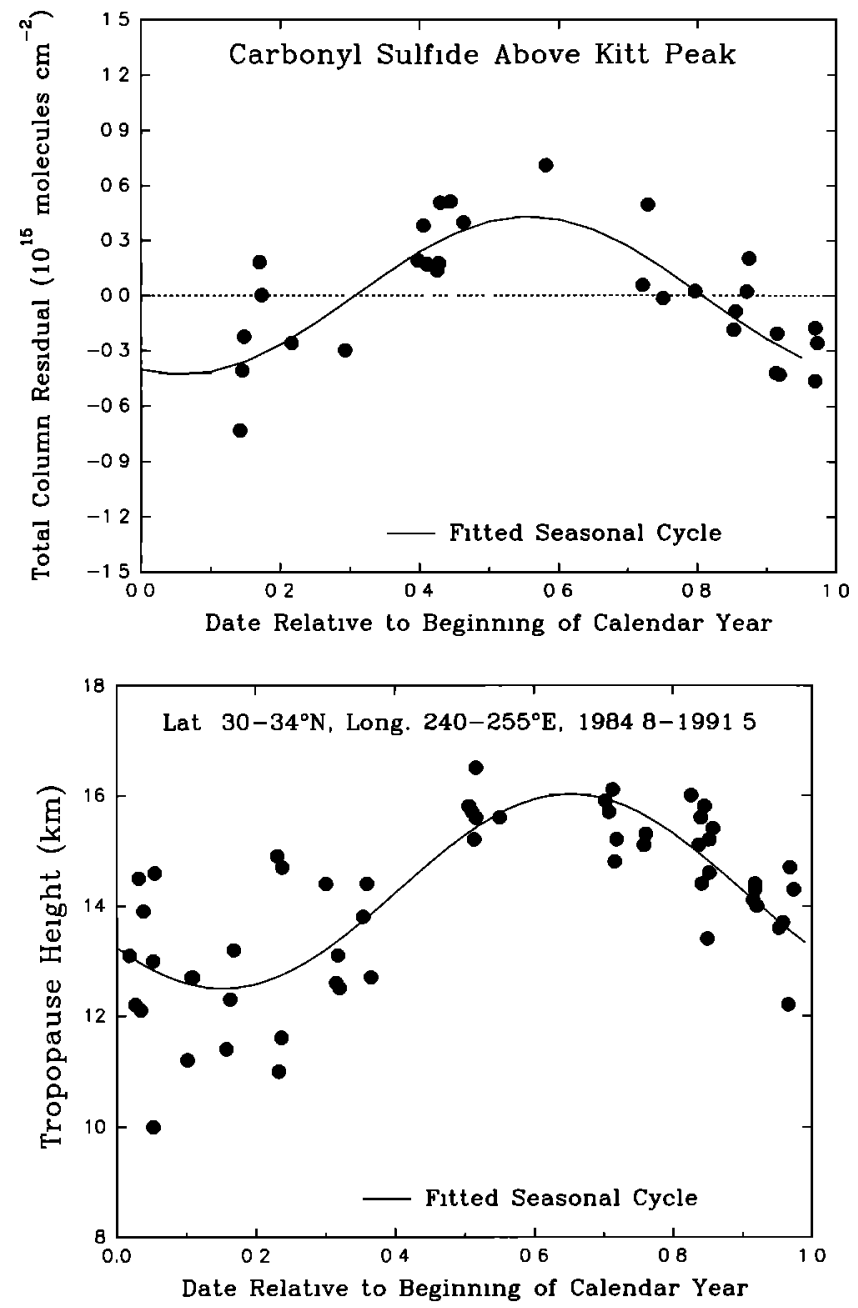

Fig. 4. (Upper panel) Kitt Peak case A total column residuals and (lower panel) a sampling of NMC tropopause height measurements for the same geographic region plotted versus season. The dashed horizontal line and the sinusoidal curve in the upper panel correspond respectively to zero residuals and the seasonal variation predicted with the case B coefficients in Table 5. The NMC tropopause heights in the lower panel are values calculated for SAGE II occultation events near Kitt Peak over the same time period (R. E. Veiga, private communication, 1991). The curve in the lower panel shows a least squares fit to the data assuming a sinusoidal variation of the tropopause height with season.

first years of observations (i.e., until about 1988.0), followed by a damping of the amplitude particularly during 1988 and 1989. Separate fittings presented in Table 5 and Figure 3 for 1984-1987 and 1984-1991 illustrate this effect $\left(a_{0}\right.$ values and $2-\sigma$ uncertainties of $0.072 \pm 0.024$ and $0.033 \pm 0.016$, respectively). A similar behavior is also observed in the column abundances of other long-lived telluric gases such as $\mathrm{CH}_{4}$ and $\mathrm{N}_{2} \mathrm{O}$ measured above ISSJ (results obtained by $\mathrm{R}$. Z.). Furthermore, the relative amplitudes of the total column seasonal variations of these long-lived gases are nearly equal, as are the phases of the variations. For example, the relative magnitude of the ISSJ seasonal component $\left(a_{0}\right.$ value) deduced from measurements in 1984 to 1987 is $(7.2 \pm$ $2.4) \%$ for OCS (Table 5, this paper) as compared to $\pm 7 \%$ for $\mathrm{CH}_{4}$ [Zander et al., 1989a]; the total columns of both gases were largest in the summer and smallest in the winter.

In Figure 5 the case A ISSJ residuals are plotted versus the

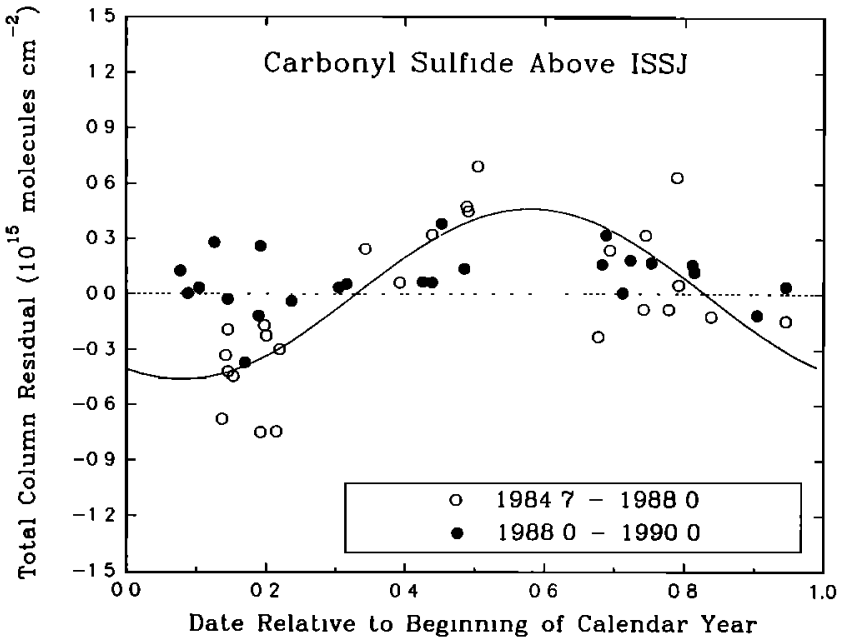

Fig. 5. ISSJ case A total column residuals plotted versus season for 1984.7 to 1988.0 and 1988.0 to 1990.0 . The solid curve shows a fit to the 1984.7-1988.0 data, assuming a sinusoidal variation.

time of the calendar year. A solid circle is used for data from 1988 and 1989, while the other data are represented with open circles. A reduction in the amplitude of the OCS seasonal variations in the winters of 1988 and 1989 is readily apparent. The cause of this effect is under investigation.

No previous information has been published on seasonal variations in OCS, but it is reasonable to assume that the maximum change in the troposphere is no more than a few percent if the lifetime of OCS is several years or more. Bingemer et al. [1990] suggested that there may be a seasonal signal caused by the uptake of OCS by vegetation. However, this would lead to a summer minimum and a winter maximum, whereas we observe the opposite seasonal variation. Loss due to reaction with $\mathrm{OH}$ would also lead to a summer minimum. Mankin et al. [1979] reported IR solar absorption measurements of OCS obtained with a FTS on an aircraft; within their measurement errors, they found no significant seasonal variation in the OCS total columns above $12 \mathrm{~km}$ (see their Figure 4).

Within the errors the measured KP and ISSJ trends reported in Table 5 are consistent; both show a long-term OCS total column growth rate that is not statistically different from zero. On the basis of the KP case B result which has the smallest uncertainty we conclude that the OCS total column amount has not changed by more than $0.2 \% \mathrm{yr}^{-1}$, $2 \sigma$, since 1977 . This result places a very stringent constraint on the long-term growth rate of OCS and any possible increase in OCS anthropogenic emissions. The inferred upper limit should be reliable because it was derived from high-quality spectra analyzed with the same techniques, using identical spectroscopic line parameters, and applied to two spectral features which have been shown in this work to yield retrieved total columns that are internally consistent. The solar absorption datasets span a long period of time (May 1977 to March 1991 for KP and October 1984 to April 1991 for ISSJ) so that a slow increase in the OCS total column would have accumulated to an amount readily detectable by our observations. Furthermore, because of the relatively long atmospheric lifetime of OCS, it is reasonable to assume that there has been no significant change in the 
OCS total column at northern mid-latitudes over the last decade.

Our measurements place a stronger constraint on the long-term OCS growth rate than the recently reported upper limit of $1 \% \mathrm{yr}^{-1}$ deduced from a comparison of OCS measurements obtained by numerous investigators since 1975 [Johnson et al., 1990]. Hofmann [1991] has also reported that the concentration of OCS does not appear to be increasing; this conclusion was based on unpublished OCS measurements obtained by R. A. Rasmussen. A trend upper limit was not cited.

As a check on our trend results, total column amounts have also been retrieved from the same ISSJ spectra using an independent set of software developed at the Jet Propulsion Laboratory (JPL) for the analysis of the ATMOS spectra [Norton and Rinsland, 1991]. The case A, long-term exponential increase rate $\beta$ derived by least squares fitting the total columns retrieved with the JPL program is $(+0.3 \pm$ $0.6) \% \mathrm{yr}^{-1}, 2 \sigma$, very close to the value reported in Table 5 .

Mean values of the daily averaged total columns are 8.44 $\times 10^{15}$ molecules $\mathrm{cm}^{-2}$ for KP and $6.41 \times 10^{15}$ molecules $\mathrm{cm}^{-2}$ for ISSJ, respectively. Assuming these values and the profile I vertical distribution for KP and the profile II vertical distribution for ISSJ, average tropospheric mixing ratios of 0.54 ppbv (parts per billion by volume) above KP and 0.52 ppbv above ISSJ are derived. Considering the systematic errors in Table 4, these values are estimated to have an absolute accuracy of $\pm 7 \%, 1 \sigma$. Within this uncertainty, our derived mean tropospheric VMRs are in good agreement with previous measurements at northern mid-latitudes [Sandalls and Penkett, 1977; Maroulis et al., 1977; Torres et al., 1980; Rasmussen et al., 1982a, b; Carroll, 1985; Johnson and Harrison, 1986; Bates and Johnson, 1990; Johnson et al., 1990].

Acknowledgments. Research at the University of Liège was supported in part by the Chemical Manufacturers Association, Washington, D. C., and by the Belgian Fonds de la Recherche Fondamentale Collective. The National Solar Observatory (NSO) FTS on Kitt Peak is operated by the Association of Universities for Research in Astronomy, Inc. (AURA) under cooperative agreement with NSF. The McMath FTS solar observations were partially supported by the U.S. Department of Energy $\mathrm{CO}_{2}$ program, NASA, the Chemical Manufacturers Association, and NSF. We thank G. Roland and L. Delbouille for their advice during the recording and processing of the Jungfraujoch FTS spectra investigated here and Claude Plymate, Jeremy Wagner, Ron Hubbard, and Michael Brown of NSO for their assistance in recording the Kitt Peak FTS spectra analyzed here. Robert Veiga of STX Corporation provided the NMC tropopause heights reported here, and Carolyn Sutton of STX Corporation helped with the computer processing of the Kitt Peak and ISSJ solar spectra at NASA Langley.

\section{REFERENCES}

Bates, T. S., and J. E. Johnson, Electron capture sulfur measurements of DMS, $\mathrm{CS}_{2}$, and OCS during CITE-3, Eos Trans. $A G U$, $71,1255,1990$.

Bingemer, H. G., S. Bürgermeister, R. L. Zimmermann. and H.-W. Georgii, Atmospheric OCS: Evidence for a contribution of anthropogenic sources? J. Geophys. Res., 95, 20,617-20,622, 1990.

Bouanich, J.-P., J. Walrand, S. Alberty, and G. Blanquet, Diodelaser measurements of oxygen-broadened linewidths in the $\nu_{1}$ band of OCS, J. Mol. Spectrosc., 123, 37-47, 1987.

Brault, J. W., Solar Fourier transform spectroscopy. in Proc. JOSO Workshop., eds. G. Godoli, G. Noci, and A. Righin, Osser. Mem. Osserv. Astrofis. Arcetri, No. 106, pp. 33-52, 1978.

Camy-Peyret, C., J.-M. Flaud, C. P. Rinsland. V. Malathy Devi.
M. A. H. Smith, and A. Goldman, Line parameters for ozone hot bands in the 4.8- $\mu \mathrm{m}$ spectral region, J. Mol. Spectrosc.. 139 , 353-360. 1990.

Carroll. M. A., Measurements of OCS and $\mathrm{CS}_{2}$ in the free troposphere, J. Geophys. Res.. 90, 10,483-10,486, 1985.

Crutzen, P. J., The possible importance of CSO for the sulfate layer of the stratosphere, Geophys. Res. Lett., 3, 73-76, 1976.

Crutzen, P. J., and M. O. Andreae, Biomass burning in the tropics: Impact on atmospheric chemistry and biogeochemical cycles, Science, 250, 1669-1678, 1990.

Delbouille, L.. G. Roland, J. Brault, and L. Testerman, Photometric Atlas of the Solar Spectrum From 1,850 to $10,000 \mathrm{~cm}^{-1}$, Kitt Peak National Observatory. Tucson, Ariz., 1981.

Ehhalt, D. H., U. Schmidt, R. Zander, P. Demoulin, and C. P. Rinsland, Seasonal cycle and secular trend of ethane in the free troposphere above the Jungfraujoch, J. Geophys. Res., 96, 49854994, 1991.

Hofmann. D. J.. Increase in the stratospheric background sulfuric acid aerosol mass in the past 10 years, Science, 248, 996-1000, 1990.

Hofmann, D. J., Aircraft sulphur emissions, Nattre, 349, 659, 1991.

Hofmann, D. J., and J. M. Rosen, Stratospheric sulfuric acid layer: Evidence for an anthropogenic component, Science, 208, 1368$1370,1980$.

Hofmann, D. J., and S. Solomon, Ozone destruction through heterogeneous chemistry following the eruption of El Chichón, $J$. Geophys. Res., 94, 5029-5041, 1989.

Inn, E. C. Y., J. F. Vedder, and D. O'Hara, Measurement of stratospheric sulfur constituents, Geophys. Res. Lett., 8, 5-8, 1981.

Johnson, J. E., The lifetime of carbonyl sulfide in the troposphere, Geophys. Res. Lett., 8, 938-940, 1981.

Johnson, J. E. and H. Harrison, Carbonyl sulfide concentrations in the surface waters and above the Pacific ocean, J. Geophys. Res., 9l, 7883-7888, 1986.

Johnson, J. E., A. Bandy, and D. Thornton, The interhemispheric gradient of carbonyl sulfide as observed during CITE-3, Eos Trans. $A G U, 7 I, 1255,1990$.

Kagann, R. H., Infrared absorption intensities for OCS, J. Mol. Spectrosc., 94, 192-198, 1982.

Khalil, M. A. K., and R. A. Rasmussen, Global sources, lifetimes and mass balances of carbonyl sulfide (OCS) and carbonyl disulfide $\left(\mathrm{CS}_{2}\right)$ in the earth's atmosphere, Atmos. Environ., I8, 1805$1813,1984$.

Louisnard, N., G. Fergant, A. Girard, L. Gramont, O. LadoBordowsky, J. Laurent. S. Le Boiteux, and M. P. Lemaitre, Infrared absorption spectroscopy applied to stratospheric profiles of minor constituents, J. Geophys. Res., 88, 5365-5376, 1983.

Malbrouck, R., Spectroscopie à très haute résolution par transformée de Fourier-Application à l'étude du spectre solaire, Ph.D. thesis, Univ. Liège, Liège, Belgium, 1977.

Mankin, W. G., M. T. Coffey, D. W. T. Griffith, and S. R. Drayson, Spectroscopic measurement of carbonyl sulfide (OCS) in the stratosphere, Geophys. Res. Lett.. 6. 853-856, 1979.

Maroulis, P. J., A. L. Torres, and A. R. Bandy, Atmospheric concentrations of carbonyl sulfide in the southwestern and eastern United States, Geophys. Res. Lett., 4, 510-512, 1977.

Norton. R. H., and C. P. Rinsland, ATMOS data processing and science analysis methods, Appl. Opt., 30, 389-400, 1991.

Rasmussen, R. A., M. A. K. Khalil, and S. D. Hoyt, The oceanic source of carbonyl sulfide (OCS), Atmos. Environ., 16, 15911594, 1982a.

Rasmussen, R. A., M. A. K. Khalil, A. J. Crawford, and P. J. Fraser, Natural and anthropogenic trace gases in the southern hemisphere, Geophys. Res. Lett., 9, 704-707, 1982 b.

Rinsland, C. P., A. Goldman, F. J. Murcray, D. G. Murcray, M. A. H. Smith, R. K. Seals, Jr., J. C. Larsen, and P. L. Rinsland, Stratospheric $\mathrm{N}_{2} \mathrm{O}$ mixing ratio profile from high-resolution balloon-borne solar absorption spectra and laboratory spectra near $1880 \mathrm{~cm}^{-1}$, Appl. Opt., 21, 435I-4355, 1982.

Rinstand. C. P., R. E. Boughner, J. C. Larsen, G. M. Stokes, and J.W. Brault, Diurnal variations of atmospheric nitric oxide: Ground-based infrared spectroscopic measurements and their interpretation with time-dependent photochemical model calculations, J. Geophys. Res., 89. 9613-9622. 1984.

Rinsland. C. P.. J. S. Levine, and T. Miles, Concentration of 
methane in the troposphere deduced from 1951 infrared solar spectra, Nature, 3/8, 245-249, 1985.

Rinsiand, C. P., M. A. H. Smith, J.-M. Flaud, C. Camy-Peyret. and $V$. Malathy Devi, Line positions and intensities of the $2 \nu_{3}, \nu_{1}+$ $\nu_{3}$, and $2 \nu_{1}$ bands of ${ }^{16} \mathrm{O}_{3}, J . \mathrm{Mol}$. Spectrosc., I30, 204-212, 1988.

Rinsland, C. P., D. W. Johnson, A. Goldman, and J. S. Levine, Evidence for a decline in the atmospheric accumulation rate of $\mathrm{CHClF}_{2}$ (CFC-22), Nature, 337, 535-537, 1989.

Rinsland, C. P., J. S. Levine, A. Goldman, N. D. Sze, M. K. W. $\mathrm{Ko}$, and D. W. Johnson, Infrared measurements of $\mathrm{HF}$ and $\mathrm{HCl}$ total column abundances above Kitt Peak, 1977-1990: Seasonal cycles, long-term increases, and comparisons with model calculations, J. Geophys. Res., 96, 15,523-15,540, 1991 a.

Rinsland, C. P., R. Zander, and P. Demoulin, Ground-based infrared measurements of $\mathrm{HNO}_{3}$ total column abundances: Long-term trend and variability, J. Geophys. Res., 96, 9379-9389, $1991 b$.

Rothman, L. S., et al., The HITRAN database: 1986 edition, Appl. Opt., 26, 4058-4097, 1987.

Sandalls, F. J., and S. A. Penkett, Measurements of carbonyl sulfide and carbon disulphide in the atmosphere, Almos. Environ., II, 197-199, 1977.

Smith, M. A. H., Compilation of atmospheric gas concentration profiles from 0 to $50 \mathrm{~km}$, NASA Tech. Mem., TM 83289, 1982. (Available as NTIS $82 N 22822$ from the Natl. Tech. Inf. Serv., Springfield, Va.)

Stokes, G. M., J. Brault, and L. Testerman, The PNL/KPNO telluric spectrum program, in technical digest of the Topical Meeting on Spectroscopy in Support of Atmospheric Measurements, Optical Society of America, Sarasota, Fla., Nov. 10-12, 1980.

Torres, A. L., P. J. Maroulis, A. B. Goldberg, and A. R. Bandy, Atmospheric OCS measurements on project Gametag, J. Geophys. Res., 85, 7357-7360, 1980.

Turco, R. P., R. C. Whitten, O. B. Toon, J. B. Pollack, and P. Hamill, OCS, stratospheric aerosols and climate, Nature. 283. 283-286, 1980.

Wells, J. S., M. Schneider, and A. G. Maki, Heterodyne frequency measurements on OCS near $61.76 \mathrm{THz}\left(2060 \mathrm{~cm}^{-1}\right), J . M o l$. Spectrosc., 140, 170-176, 1990.

World Meteorological Organization, Atmospheric ozone 1985Assessment of our understanding of the processes controlling its present distribution and change, Rep. 16, World Meteorol. Org., Geneva, 1986

Zander, R., C. P. Rinsland, C. B. Farmer, J. Namkung, R. H. Norton, and J. M. Russell III, Concentrations of carbonyl sulfide and hydrogen cyanide in the free upper troposphere and lower stratosphere deduced from ATMOS/Spacelab 3 infrared solar occultation spectra, J. Geophys. Res., 93, 1669-1678, 1988.

Zander, R., P. Demoulin, D. H. Ehhalt, and U. Schmidt, Secular increase of the vertical column abundance of methane derived from IR solar spectra recorded at the Jungfraujoch station, $J$. Geophys. Res., 94, 11,029-11,039, 1989a.

Zander, R., P. Demoulin, D. H. Ehhalt, U. Schmidt, and C. P. Rinsland, Secular increase of the total vertical column abundance of carbon monoxide above central Europe since 1950, J. Geophys. Res., 94, 11,021-11,028, 1989b.

Zander, R., C. P. Rinsland, and P. Demoulin, Infrared spectroscopic measurements of the vertical column abundance of sulfur hexafluoride, $\mathrm{SF}_{6}$, from the ground, J. Geophys. Res., 96, 15,447$15,454,1991$.

P. Demoulin, E. Mahieu, and R. Zander, Institute of Astrophysics. University of Liège, Liège-Cointe, B4000 Belgium.

D. H. Ehhalt and J. Rudolph, Institut für Atmosphärische Chemie, Forschungszentrum Jülich, Jülich, D5170 Germany.

A. Goldman, Department of Physics, University of Denver, Denver, CO 80208.

C. P. Rinsland, Atmospheric Sciences Division, NASA Langley Research Center, Hampton, VA 23665.

(Received September 30, 1991; revised January 3, 1992; accepted January 3, 1992.) 